\title{
Cinema e literatura: pesquisa-ação na Educação de Jovens e Adultos ${ }^{1}$
}

\author{
Denise Stefanoni Combinato* \\ João Mário de Medeiros Paixão**
}

\begin{abstract}
Resumo
$\mathrm{Na}$ expectativa de contribuir com a Educação de Jovens e Adultos, foi proposto um projeto de pesquisa-ação em uma Escola Estadual. O objetivo foi promover os aspectos educativos, culturais e pessoais por meio de exibições e discussões baseadas em filmes e textos literários. Buscou-se estimular a reflexão dos alunos sobre as informações recebidas através do cinema, da literatura e de outros meios de comunicação. Os resultados obtidos serão descritos e analisados a partir do recorte de um dos encontros sobre o trabalho e o processo de produção no cinema, articulados à literatura e à experiência de trabalho dos próprios alunos.

Palavras-chave: Educação de Jovens e Adultos; cinema; literatura, pesquisa-ação.
\end{abstract}

\section{Cinema and literature: action research on Youth and Adult Education}

\begin{abstract}
Expecting to contribute to the Youth and Adults Education an action research project was proposed in a State School. The goal was to promote educational, cultural and personal aspects through exhibitions and discussions based on films and literature. It sought to stimulate the students' reflection about the information received through cinema, literature and other media. The results will be described and analyzed from a cut of one of the meetings about the work and production process of cinema, articulated with literature and the student's own work experiences.

Keywords: Youth and Adult Education; cinema; literature; action research.
\end{abstract}

\section{Introdução}

O desenvolvimento humano depende da apropriação daquilo que foi produzido historicamente pela humanidade, seja produção material ou imaterial (LEONTIEV, 1978), e é papel da escola promover o acesso ao conhecimento sistematizado (SAVIANI, 1992).

Esse conhecimento, por sua vez, deve extrapolar os conteúdos de ciência e tecnologia puras. Tais conteúdos são parte (não o todo) da formação, embora esta tenha ênfase em sociedades capitalistas e tecnicistas.

A arte compõe (ou deveria compor) a formação humana, na medida em que responde a uma necessidade humana universal (CANDIDO, 1988), possibilita a leitura e a apropriação da realidade (SCHROEDER, 2012) e promove a formação ética (ZANELLA et al., 2006; LOPES, 2012), ao incorporar a multiplicidade, a diferença, a contradição, o questionamento.

Assim, entende-se a escola como um espaço privilegiado na promoção da "educação do sensível":

Por meio da experiência estética o homem desenvolve a capacidade sensível, a percepção, e constrói um olhar que o incentiva a perceber a

\footnotetext{
*Endereço Eletrônico: denisesc@ita.br

***Endereço Eletrônico: joaomario@aluno.ita.br
}

realidade de diversos ângulos, sob diversos aspectos (CAMARGO; BULGACOV, 2008, p.249).

Uma dessas experiências estéticas é o cinema. Criado no final do século XIX pelos irmãos Lumière, o cinema, que iniciou retratando cenas do cotidiano da cidade, passou rapidamente a inventar uma realidade através da "gramática cinematográfica" (DUARTE, 2009, p.33): “O aparato técnico inventado para registrar o mundo passaria, também, a recriá-lo, segundo novas regras e artifícios ou, ainda, a criar outros mundos" (DUARTE, 2009, p.24).

Combinando imagens em movimento, iluminação, som, texto e fala, o cinema consegue captar a atenção e seduzir o espectador (DUARTE, 2009), produzir sentidos singulares (BERTI; CARVALHO, 2013) e promover a reflexão sobre a própria vida (DUARTE, 2009).

Foi com o objetivo de promover os aspectos educativos, culturais e pessoais dos alunos da Educação de Jovens e Adultos que iniciamos o projeto de pesquisa-ação "A Tecnologia do Cinema na Construção da Educação e da Cidadania".

A história da Educação de Jovens e Adultos iniciou-se no Brasil na década de 1940. Nos anos 60, movimentos de educação e cultura popular 
ligados à Igreja Católica e aos ensinamentos de Paulo Freire buscaram promover a alfabetização aliada à experiência de vida dessas pessoas, tendo em vista a análise crítica da realidade e a intervenção social. Com a Ditadura Militar, na década de 1970, a ênfase desse ensino foi alterada drasticamente. Foi criado o Movimento Brasileiro de Alfabetização (MOBRAL), com função de repor a escolaridade não realizada anteriormente para atender às necessidades de recursos humanos (DI PIERRO, 2005).

Em defesa da educação como um bem coletivo, a década de 1990 foi caracterizada como a "Década da Educação para Todos". Conferências e comissões internacionais defendiam o acesso ao ensino de qualidade a todos e a redução do analfabetismo (DI PIERRO, 2010).

No Brasil, a Lei de Diretrizes e Bases da Educação Nacional (Lei n. 9394, BRASIL, 1996) reafirmou o direito de jovens e adultos à educação:

Art. $4^{\circ}$. O dever do Estado com a educação escolar pública será efetivado mediante a garantia de:

I - educação básica obrigatória e gratuita dos 4 (quatro) aos 17 (dezessete) anos de idade [...]

IV - acesso público e gratuito aos ensinos fundamental e médio para todos os que não os concluíram na idade própria;

VII - oferta de educação escolar regular para jovens e adultos, com características e modalidades adequadas às suas necessidades e disponibilidades, garantindo-se aos que forem trabalhadores as condições de acesso e permanência na escola.

Entretanto, o incentivo político e financeiro não correspondeu à afirmação legal, sendo o investimento público focalizado na educação de crianças e adolescentes (DI PIERRO, 2010). A autora explica que, por um lado, havia

consenso em favor da alfabetização e da educação como esteios da participação cidadã na sociedade democrática e da qualificação profissional [...], o que se refletiu no alargamento dos direitos educativos dos jovens e adultos consagrados na legislação. Por outro lado, a educação de jovens e adultos ocupou lugar marginal na reforma educacional da segunda metade dos anos de 1990, implementada sob o condicionamento das prescrições neoliberais de reforma do Estado e restrição ao gasto público (DI PIERRO, 2005, p.1123).
Avanços importantes na política educacional aconteceram na década de 2000 para a Educação de Jovens e Adultos (inclusão de mecanismos de financiamento e ampliação de iniciativas de EJA); no entanto, os resultados obtidos ainda foram pequenos (DI PIERRO, 2010) ${ }^{2}$.

Além de superar as políticas marginais, transitórias e simplistas para a Educação de Jovens e Adultos, é preciso articular políticas que extrapolem a esfera educacional (DI PIERRO, 2005, 2010), atuando "conjuntamente sobre as condições estruturais de exclusão política socioeconômica e cultural que geram e reproduzem tais fenômenos" (DI PIERRO, 2010, p.953).

Dentro dos limites impostos pela política educacional e na expectativa de contribuir com a Educação de Jovens e Adultos, propusemos um projeto afirmando a missão da Universidade Pública de articular ensino-pesquisa-extensão.

\section{Sobre a pesquisa-ação}

Foram selecionados alunos de Engenharia para participar do projeto vinculado ao Programa Institucional de Bolsas de Iniciação Científica PIBIC / CNPq. No período de 2012 a 2015, quatro alunos estiveram envolvidos no projeto; um deles é coautor deste artigo e permaneceu no projeto por três anos consecutivos, encerrando sua participação no último ano da graduação.

O trabalho foi desenvolvido em uma escola estadual, situada em um bairro central do município de São José dos Campos/SP. A escola oferece Ensino Fundamental e Médio, incluindo a Educação de Jovens e Adultos no período noturno. Segundo dados do Censo Escolar de 2014 do INEP (BRASIL, 2014), naquele ano a escola contava com 153 funcionários e 1629 alunos, dos quais 299 cursavam a EJA. Sua infraestrutura contava com 20 salas de aula, uma biblioteca e um auditório, o qual foi utilizado em alguns encontros.

Em cada ano (agosto/2012 a junho/2013; agosto/2013 a junho/2014; agosto/2014 a junho/2015), trabalhamos com uma turma de Educação de Jovens e Adultos, do período em que estiveram matriculados no $2^{\circ}$ ano do Ensino Médio ao encerramento do $3^{\circ}$ ano do Ensino Médio. O número de alunos variava ao longo do semestre, diminuindo com o decorrer do tempo. Em determinados dias da semana, também era possível verificar que a ausência era mais comum, como nas quartas-feiras, em decorrência de jogos de futebol transmitidos pela televisão. 
Exceto no primeiro ano do projeto, em que predominava o público jovem, nos anos seguintes, as turmas selecionadas eram bastante heterogêneas, com público na faixa etária entre 18 a 57 anos. A maioria era trabalhador (mecânico, motorista, eletricista, empregada doméstica, diarista, camareira, auxiliar administrativo, militar de baixo escalão) e buscava alcançar melhores condições de vida e trabalho através da elevação educacional.

Os encontros aconteciam mensalmente, em horário regular de aula (das 19 às 20h30), com datas agendadas previamente de acordo com a disponibilidade fornecida pelo Coordenador Pedagógico do período noturno da escola.

No período entre os encontros, a equipe, composta por alunos de Iniciação Científica e professoras-pesquisadoras, estudava temas relacionados ao projeto (Educação de Jovens e Adultos, trabalho grupal, cinema, literatura e educação, por exemplo); avaliava o encontro anterior com base em questionários e textos escritos pelos alunos, além das observações registradas em diário de campo; e planejava o encontro seguinte.

Foram realizadas discussões temáticas e sobre a linguagem cinematográfica, buscando articular as experiências dos alunos e o conhecimento adquirido em algumas disciplinas, como, por exemplo, Língua Portuguesa/Literatura e História. Alguns temas abordados nos encontros foram: as funções da escrita; o processo de produção de obras literárias e cinematográficas; o som no cinema; metáfora e símbolo no cinema; fotografia no cinema. Após o encontro em que foram abordados os símbolos e as metáforas no cinema, por exemplo, uma aluna falou espontaneamente: "agora entendi o que é metáfora".

As discussões realizadas em sala desempenharam um importante papel na tentativa de proporcionar aos alunos reflexões que os tornassem capazes de desenvolver ainda mais o seu espírito crítico e de reconhecer a importância da aprendizagem adquirida em suas vidas, pois como afirma Saraiva (2013, p.1):

Dificilmente alguém alcançará realização como pessoa ou profissional, se não tiver formado espírito crítico sobre si mesmo, sobre a realidade que o cerca, permitindo-lhe a formação de conceitos seguros, válidos no presente e no futuro, como ponto de referência, porque resultantes de um espírito crítico bem formado, de uma consciência lúcida.

Neste texto, especificamente, faremos a descrição e a análise de um dos encontros em que abordamos a temática "trabalho" e o processo de produção no cinema, articulados à literatura e à experiência de trabalho dos próprios alunos. Como se trata de uma pesquisa-ação, optamos por descrever e analisar de maneira mais aprofundada um único encontro, a fim de elucidar o procedimento utilizado e os resultados alcançados neste momento e, de maneira geral, no projeto.

\section{Encontro sobre trabalhos \& trabalhos}

Com base na Pedagogia histórico-crítica e Psicologia histórico-cultural, os conteúdos eram abordados nos encontros de forma contextualizada, tendo como ponto de partida a realidade social e o conhecimento dos alunos. Gasparin (2005) apresenta, fundamentado no método dialético, cinco etapas para o desenvolvimento de atividades educativas (Prática Social Inicial do Conteúdo, Problematização, Instrumentalização, Catarse e Prática Social Final do Conteúdo), que serão descritas ao longo desta seção.

Nesse encontro sobre trabalhos \& trabalhos, expusemos aos alunos a temática proposta para aquele dia e questionamos sobre suas atividades profissionais, com objetivo de mobilizá-los para o tema do encontro (processo de produção/trabalho), integrando-o ao contexto de vida dos alunos. Algumas questões apresentadas aos alunos foram: como se caracteriza seu trabalho: é realizado individualmente ou em grupo? Você sabe qual é o resultado/produto final do seu trabalho? Você acompanha ou participa de todo o processo? Se sim, de que maneira? Você tem autonomia no seu trabalho? Como você se sente no trabalho?

Conforme cada questão era apresentada, um ou outro aluno se manifestava. Alguns responderam que tinham autonomia e acompanhavam o processo de produção (mecânico de automóveis, por exemplo), que gostavam da atividade desempenhada, mas que a profissão não era reconhecida e valorizada socialmente. Outros falaram que tinham autonomia parcial e acrescentaram que, geralmente, em grandes empresas/fábricas, é difícil possuir autonomia. Outros comentaram, inicialmente, que trabalhavam sozinhos. Quando pedíamos que descrevessem a atividade, percebíamos que não era exatamente um trabalho individual. Então fazíamos perguntas para que os alunos percebessem também essas interfaces e interlocuções com outros setores/profissionais.

Compreender como se dá o processo de 
trabalho (e alienação) é, de certa maneira, compreender a própria identidade. Isso porque o homem constitui-se a partir do trabalho. O trabalho caracteriza-se por um processo de transformação entre homem e natureza, para atender a uma necessidade humana:

Pela sua actividade, os homens não fazem senão adaptar-se à natureza. Eles modificam-na em função do desenvolvimento das suas necessidades [...] Constroem habitações, produzem as suas roupas e os bens materiais. Os progressos realizados na produção de bens materiais são acompanhados pelo desenvolvimento da cultura dos homens; o seu conhecimento do mundo circundante deles mesmos enriquece-se, desenvolvem-se a ciência e a arte (LEONTIEV, 1978, p.265).

Fica claro aqui que o trabalho não visa apenas atender às necessidades básicas de sobrevivência (inclusive essas necessidades são afetadas pelo desenvolvimento histórico-social), mas também àquelas criadas socialmente, como é o caso da arte.

Concluída essa primeira etapa (Prática Social Inicial do Conteúdo, Gasparin, 2005), em que são apresentados tema e objetivo do encontro e os alunos são estimulados a apresentar conhecimento e experiências que têm sobre o assunto, propusemos a leitura do texto "O açúcar", de Ferreira Gullar (GULLAR, 1975), com o objetivo de problematizar o tema "trabalho" e relacioná-lo com as respostas emitidas pelos alunos na etapa anterior. No poema, o escritor traça o processo de produção do açúcar, desde o plantio até chegar à mesa do consumidor, refletindo sobre a força de trabalho e a contradição existente entre os homens de vida amarga e dura que, em usinas escuras, produziram aquele açúcar branco e puro que adoçara seu - do leitor - café naquela manhã em Ipanema. A Problematização, segundo Gasparin (2005, p.35), "é um elemento chave na transição entre a prática e a teoria, isto é, entre o fazer cotidiano e a cultura elaborada". Isso porque cria uma necessidade no educando e mobiliza-o na busca do conhecimento.

Após problematizar as contradições envolvidas no processo de trabalho, deu-se início à etapa seguinte do encontro, etapa de Instrumentalização, ou seja, a explicitação do conteúdo (GASPARIN, 2005) sobre o processo de produção do livro e do filme.

Foi abordado como se dá o processo de elaboração do texto literário a partir da apresentação de um livro de Guimarães Rosa (ROSA, 2011), da explicitação das diferenças no processo de trabalho de diversos escritores (Guimarães Rosa e Clarice Lispector, por exemplo), da citação de trechos sobre o processo de escrita de Umberto Eco (ECO, 2013) e José Saramago (AGUILERA, 2010).

O trabalho de pesquisa de campo desenvolvido pelo escritor Guimarães Rosa foi apresentado com o auxílio de um livro fac-símile (ROSA, 2011) que traz anotações que o autor fez durante expedição realizada em 1952, pelas veredas do Sertão de Minas Gerais. O papel desempenhado pelos profissionais envolvidos na elaboração das capas e artes internas de seus livros, o qual tomava como base inclusive os desenhos do próprio autor, foi ilustrado para a turma através da arte de Luiz Jardim para o livro "Primeiras Estórias" (ROSA, 1969).

Os hábitos de escrita de autores como Clarice Lispector, Vladimir Nabokov, Truman Capote e Friedrich Schiller também foram expostos na aula. Essa discussão acabou por levar a uma reflexão, proposta para a turma, sobre os aspectos de "transpiração" e "inspiração" envolvidos na atividade de criação literária, com base em reflexões dos escritores José Saramago, Umberto Eco e do cientista Thomas Edison. Sem negar o papel da inspiração, os autores defendem que o trabalho, metaforizado na "transpiração", é significativamente maior que a inspiração. Com isso, procuramos desmistificar a ideia de que o trabalho criativo, de modo geral, e artístico, em específico, não demanda grande "transpiração", esforço ou dedicação.

Estendendo a discussão para o campo de trabalho dos envolvidos na produção cinematográfica, realizou-se a exibição de um trecho do filme "A Liberdade é Azul", de 1993, do cineasta polonês Krzysztof Kieslowski ${ }^{3}$. Na cena, que se passa em uma cafeteria, a personagem principal tem um reencontro inesperado com o passado do qual tentava fugir. Entretanto, apesar da importância do acontecimento, ela permanece atenta aos pequenos detalhes, como o café e o açúcar que se encontram em sua mesa, demonstrando a elevada introspecção na qual mergulhou após a perda de seus parentes em um trágico acidente de automóvel. 
Figura 1. Cena do filme "A Liberdade é Azul” do cineasta polonês Krzysztof Kieslowski, de 1993.

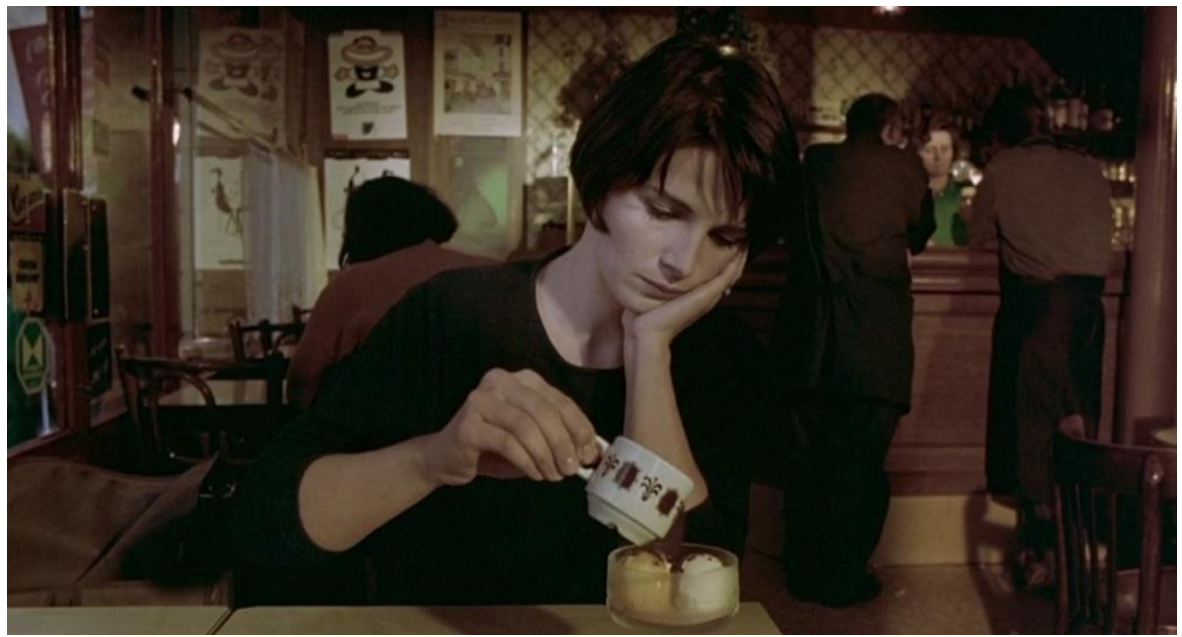

Fonte: http://pqpbach.sul21.com.br/2014/11/10/zbigniew-preisner-1955-trois-couleurs-bleu-a-liberdade-e-azulew/

Em um primeiro momento, a cena foi exibida e os alunos incentivados a se questionar sobre as sutilezas utilizadas pelos profissionais do cinema em sua elaboração. Seguiu-se então uma apresentação sobre o processo de produção de um filme (roteiro, captação de recursos financeiros, préprodução, filmagem, pós-produção, distribuição) e sobre os principais profissionais envolvidos em sua criação (roteirista, diretor de arte, diretor de fotografia, técnico de som, diretor, montador, produtor).

Por fim, foi exibida uma entrevista na qual o diretor Krzysztof Kieslowski abordava o trabalho "por trás das câmeras" realizado por ele e seus assistentes, os principais aspectos técnicos e temáticos envolvidos na construção daquela cena e suas expectativas quanto à impressão que o público poderia ter ao assisti-la.

Com isso, foi possível fechar o ciclo de discussões sobre trabalho, motivando os alunos a refletir sobre as principais características envolvidas em suas profissões, bem como naquelas dos envolvidos na produção literária e cinematográfica, buscando os pontos de contato existentes entre tais atividades.

No encerramento do encontro, fez-se uma síntese e avaliação do conteúdo. De acordo com Gasparin (2005, p.128),

a catarse é a síntese do cotidiano e do científico, do teórico e do prático a que o educando chegou [...] Significa, outrossim, a conclusão, o resumo que ele faz do conteúdo aprendido recentemente. É o novo ponto teórico de chegada; a manifestação do novo conceito adquirido.
A partir dessa nova síntese, espera-se que o educando tenha uma nova compreensão e um novo posicionamento social. Ao retornar à Prática Social (agora Prática Social Final), espera-se uma nova atitude prática e uma proposta de ação que articulem educação e sociedade, dentro de uma perspectiva de transformação social.

\section{Frutos ou açúcares do trabalho}

Vários foram os limites deste trabalho: o reduzido tempo de contato com cada turma (uma hora e meia por mês) ${ }^{4}$ que, por sua vez, não está desvinculado do reduzido tempo de cada turma na Educação de Jovens e Adultos na Escola (um ano e meio no Ensino Médio); a especificidade de um conteúdo (especialmente o cinema) discutido com um público que, no geral, não tem repertório na área, o que inviabiliza, em tão pouco tempo, a apropriação completa e por todos daquele conhecimento; a pouca abrangência do trabalho para o público da Educação de Jovens e Adultos na escola (uma única turma por ano); o isolamento deste trabalho em relação às atividades de ensino ${ }^{5}$.

De qualquer maneira, percebíamos um ou outro aluno interessado, participativo, que se apropriava do conteúdo abordado por nós ou parte dele; um ou outro aluno que se alegrava quando nos reencontrava na escola para um novo encontro; um ou outro aluno que, no início do projeto, não demonstrava qualquer interesse nas atividades, mas que, ao longo dos encontros, levantava a cabeça para nos ouvir, aproximava-se e participava das discussões. Houve um aluno que, no encerramento do último encontro, quando presenteamos cada um 
deles com um bombom e uma frase de algum cineasta, devolveu-nos o bombom e disse que eram eles que precisavam nos presentear.

Dadas as adversidades da escola pública e da Educação de Jovens e Adultos e, mais amplamente, da condição de vida e trabalho desses alunos, qualquer manifestação de interesse e apropriação durante os encontros (atenção concentrada, participação nas discussões, análise crítica), era considerado um resultado positivo para nós. A seguir, destacaremos os resultados específicos do encontro relatado.

A avaliação de cada um dos encontros era realizada por meio de um questionário escrito individualmente, somada à avaliação da equipe de pesquisadores sobre a atividade e seus resultados. Embora nosso entendimento seja de que a avaliação não se restringe a uma avaliação formal nem ocorre apenas no final do encontro ou do projeto, optamos por integrar um questionário avaliativo à avaliação das observações da equipe sobre os comportamentos dos alunos em sala de aula. Os alunos eram convidados a avaliar o encontro de maneira geral (ótimo, bom, regular, ruim e péssimo) e tecer comentários sobre o conteúdo abordado, além de dizer se este contribuiu ou não com sua formação. ${ }^{6}$

De maneira geral, o encontro descrito recebeu uma avaliação positiva dos alunos. Nos questionários preenchidos por eles ao final do encontro, de 21 alunos, 20 classificaram o encontro como ótimo ou bom e um aluno avaliou o encontro como regular.

Algumas respostas obtidas no questionário sobre contribuições referem-se à apropriação do conhecimento sobre o processo de produção no cinema e na literatura:

"Obtive conhecimentos que não tinha sobre como fazer um filme, e achei muito interessante a parte da fotografia.",

Em outro comentário, um dos alunos revelou a compreensão da existência do trabalho em equipe:

"Aprendemos muito hoje sobre como é feito o trabalho em conjunto no cinema e como é feito o livro."

Ao longo do encontro, chamamos atenção para a dependência existente no processo de trabalho e a importância da equipe de trabalho. Enquanto o livro "A Boiada" (ROSA, 2011) circulava pela sala de aula, foi solicitado aos alunos que observassem o verso de sua primeira página, na qual constava a equipe editorial que o produziu. Assim, buscava-se evidenciar a existência das pessoas "por trás da obra" que era manuseada. No âmbito do cinema, ideia semelhante foi ilustrada por meio da exibição da entrevista com Krzysztof Kieslowski, diretor do filme "A Liberdade é Azul".

Porém, reconhecer que esse trabalho no cinema e na literatura existe é apenas o primeiro passo. A importância de se valorizar esses profissionais, que muitas vezes são esquecidos até mesmo por aqueles que apreciam tais obras, foi mencionada por outro aluno:

"Gostei muito da maneira da construção de um livro e pelo tempo que leva para terminar. A gente que lê pouco, não damos muito valor a isso."

Outros se referiram à articulação estabelecida do conteúdo exposto com as suas vidas e seus trabalhos, um dos principais objetivos do encontro, e que teve ressonância tanto nas discussões realizadas em sala de aula quanto nas respostas aos questionários:

"Aprendi que tudo o que fazemos tem um processo muito grande."

"[Aprendi] a valorizar tudo desde o começo, e a dar valor às pessoas que trabalham em sua equipe, e me fez dar valor ao meu trabalho também."

A avaliação de um conteúdo, conforme explicita Gasparin (2005), envolve uma síntese do conteúdo e uma nova ação social. Dada a característica do projeto e o curto tempo que passamos com esses alunos, não foi possível avaliar se esse conteúdo provocou algum novo posicionamento social ou nova atitude prática; mas, em termos de síntese do conteúdo, esse relato sobre o reconhecimento do processo de trabalho e a interdependência entre as atividades e os profissionais demonstra que atingimos nosso objetivo, ainda que parcialmente.

Tanto neste encontro, como em outros realizados ao longo do projeto, buscou-se chamar a atenção dos alunos para a importância de se perceber as sutilezas presentes em obras com elevado grau de elaboração. Assim, na cena apresentada, são os pequenos detalhes, como o enquadramento da câmera em uma simples xícara de café, que ajudam a revelar o estado emocional da personagem, e não um diálogo em tom melodramático.

Por sua vez, na obra de Guimarães Rosa, os neologismos e as ilustrações desempenham papel semelhante. Utilizando-se dos neologismos, o autor ultrapassa as fronteiras ainda inexploradas de nossa língua para revelar o verdadeiro estado de seus personagens e do ambiente no qual se encontram através da criação das palavras mais adequadas para 
descrever aquilo que, até a elaboração de sua obra, era indescritível. E quando as palavras não são mais suficientes para desempenhar tal tarefa, eis que surgem as ilustrações, expressando o que até mesmo as letras da caneta de um grande escritor seriam incapazes de descrever. Aqui, o ilustrador auxilia o escritor assim como, no caso anterior, o diretor de fotografia auxilia o diretor da obra.

Assim, a compreensão do papel destes pequenos detalhes, como um simples enquadramento em um filme ou o uso de neologismos e ilustrações em um livro, mostra-se fundamental para uma interpretação mais aprofundada dessas obras. Para os expectadores e leitores mais atentos, quando Kieslowski posiciona a câmera em algo aparentemente irrelevante ou quando Rosa cria uma nova palavra, sabe-se que há algo de especial a ser descoberto por trás daquelas imagens e palavras.

Os alunos demonstraram compreender a importância dessa mensagem com os seguintes comentários:

\section{"[Aprendi] a importância dos pequenos detalhes" \\ "Me fez refletir muitas coisas em pequenos detalhes"}

Os espaços que os autores deixam nestes "pequenos detalhes" para que seu público contribua com a construção da obra podem permanecer vazios quando análises mais superficiais são realizadas. Buscou-se explicar à turma que toda obra começa na imaginação de um artista, mas não se esgota nele. Primeiro porque a imaginação é consequência de um intenso processo de apropriação social, seja na constituição dessa função psíquica superior, juntamente com linguagem, pensamento, memória, seja para fornecer conteúdos a serem transformados pela imaginação. De acordo com Martins (2013, p.227), "a imaginação suplanta a experiência sensorial prévia"; isso porque "a singularidade da imaginação reside em que, nela, as imagens das experiências prévias se alteram, produzindo outras e novas imagens". Em segundo lugar, a obra dialoga com seus leitores e espectadores, permitindo novas conexões, novas imaginações, depois de finalizada. Ou seja, a obra permite ao leitor/espectador, através da imaginação, assimilar algo que não se tenha vivido, ampliando a experiência do indivíduo (VIGOTSKI, 2003 apud MARTINS, 2013); permite ainda que leitores/espectadores completem, imaginem textos e espaços anunciados, mas não fechados, pelo artista. Queirós (2012, p.61) sintetiza de forma poética tal informação:
Cada palavra descortina um horizonte, cada frase anuncia outra estação. E os olhos, tomando das rédeas, abrem caminhos, entre linhas, para as viagens do pensamento. O livro é passaporte, é bilhete de partida.

A leitura guarda espaço para o leitor imaginar sua própria humanidade e apropriar-se de sua fragilidade, com seus sonhos, seus devaneios e sua experiência. A leitura acorda no sujeito dizeres insuspeitados enquanto redimensiona seus entendimentos.

Embora o preenchimento destes espaços exija um maior esforço de atenção por parte do público, a gama de interpretações e reflexões que delas surgem constituem o seu grande diferencial.

Ao se referirem diversas vezes à percepção dos pequenos detalhes, inclusive nos encontros posteriores a este, vários alunos demonstraram ter compreendido essa mensagem.

\section{Considerações finais ou passos iniciais}

A introdução do cinema atrelado à literatura no ambiente escolar não é relevante apenas no que se refere à educação audiovisual dos alunos. A interação entre as diversas linguagens artísticas (estéticas, sonoras, visuais) presentes nestas obras mobiliza uma série de operações mentais que podem contribuir efetivamente para o enriquecimento das funções psíquicas superiores (percepção, pensamento, linguagem e imaginação, por exemplo), na reflexão e discussão dos alunos, as quais são extremamente relevantes em outras áreas, como as de leitura e escrita.

Ao se estabelecer um vínculo entre $o$ processo de leitura hipertextual das imagens e sons presentes na obra cinematográfica e a produção escrita, o grupo buscou tornar esta prática mais dinâmica e interessante para os alunos. $\mathrm{O}$ estímulo à leitura literária, por sua vez, foi pensado para promover a formação de leitores produtores de sentido e não meros receptadores de textos.

Assim, buscou-se com este projeto estimular uma maior reflexão dos alunos sobre o tipo de informação que chega até eles, seja através da leitura, do cinema, ou dos demais meios de comunicação. Isto pressupõe o desenvolvimento de uma consciência crítica, atenta não só aos aspectos explícitos das mensagens transmitidas pelos diversos meios de comunicação, mas também aos seus aspectos implícitos.

Especificamente no encontro detalhado neste artigo, o objetivo foi promover uma discussão 
sobre o processo de trabalho envolvido na literatura e no cinema, integrando-o ao contexto de vida dos alunos.

Acredita-se que a forma utilizada para a abordagem dos conteúdos (fundamentada na Pedagogia histórico-crítica e na Psicologia histórico-cultural), envolvendo a mobilização e participação dos alunos, contribuiu significativamente para a obtenção dos resultados.

Nas interações realizadas com os alunos, ao longo do projeto, foi possível observar que uma parcela considerável da turma se sentia estimulada a ler ou propensa a assistir a mais filmes, embora nem sempre conseguissem encontrar tempo para realizar tais atividades.

Por outro lado, a abordagem dos aspectos técnicos envolvidos nas produções cinematográficas e literárias despertou o interesse dos alunos em enxergar o cinema e a literatura não apenas como formas de entretenimento, mas também como instrumentos de manifestação da cultura. Embora isso nem sempre se traduzisse em um real aumento na frequência com que assistiam a filmes ou liam, representou, ao menos, um primeiro passo nessa direção. No encontro realizado, por exemplo, dos vinte $\mathrm{e}$ um alunos que preencheram os questionários, apenas seis revelaram ter assistido a algum filme completo no mês anterior, enquanto apenas quatro indicaram ter lido algum livro no mesmo período.

$\mathrm{O}$ recorrente uso que os alunos fizeram da palavra "atenção" ("prestar mais atenção", "observar com mais atenção"), quando respondiam aos questionários, fornece um indício de que a primeira etapa deste processo foi, ao menos, iniciada. Iniciada porque o período de contato com cada turma era extremamente limitado, decorrente da própria maneira como a EJA encontra-se estruturada, impondo a necessidade de se veicular uma grande quantidade de conteúdo em um escasso tempo. Daí surge a questão: como transmitir, neste limitado número de horas, para três turmas diferentes e compostas de gerações com distintas compreensões acerca dos assuntos tratados em sala de aula, a importância da leitura, do cinema e, mais que isto, como estimular uma maior atenção para essas obras no sentido de proporcionar uma reflexão crítica dos assuntos discutidos?

Optamos por promover "passos iniciais", fornecendo os elementos básicos para uma compreensão mais aprofundada das obras literárias e cinematográficas, atentando para seus conteúdos implícitos, e que pudessem dar subsídio para os passos seguintes dos próprios alunos na apropriação da cultura para o seu desenvolvimento.

\section{Notas}

1 Apoio: CNPq (bolsa de Iniciação Científica). Agradecimentos: aos alunos da EJA, aos coordenadores pedagógicos da Escola Estadual e aos pesquisadores que fizeram parte deste projeto.

2 Di Pierro (2005; 2010) descreve e avalia detalhadamente dados de 2001 a 2009 referentes à Educação de Jovens e Adultos no Brasil.

3 Ao longo do projeto, foram selecionados especialmente filmes de autor com produção independente.

4 Além disso, entre um semestre e outro, havia alterações nas turmas, o que acarretava a perda da continuidade do trabalho para alguns alunos.

5 Além de não participarmos de qualquer planejamento pedagógico ou atividade com os professores das turmas, durante nossas aulas, raramente os professores, responsáveis pelas aulas que ocupávamos, participavam das nossas atividades. Entendemos que esses limites extrapolam nossa responsabilidade. Mesmo assim, no último ano do projeto, propusemos ampliar esse trabalho, em parceria com os professores do Ensino Médio. Poucos professores manifestaram interesse e participaram da discussão para a elaboração de um projeto de pesquisa que foi submetido à Fapesp e recentemente aprovado. A proposta da pesquisa é, através de uma pesquisaação, investigar se há e quais são os impactos da articulação da arte literária com o audiovisual no processo de ensino-aprendizagem.

6 Embora os alunos não tenham participado da concepção do projeto, a proposta era apresentada à turma no primeiro encontro, a fim de verificar se tinham interesse. Ao longo do processo, as avaliações e sugestões eram consideradas e, na medida do possível, incorporadas nos encontros seguintes. Nos questionários havia um espaço destinado especificamente para tais sugestões.

7 Os relatos são reproduzidos, aqui, tais como foram escritos pelos alunos nas avaliações.

\section{Referências}

AGUILERA, F. G. José Saramago nas suas palavras. 2.ed. Alfragide/Portugal: Editorial Caminho, 2010. 
BERTI, A.; CARVALHO, R. M. O Cine Debate promovendo encontros do cinema com a escola. Pro-Posições, v.24, n.3, p.183-199, 2013.

Disponível em:

http://www.scielo.br/pdf/pp/v24n3/11.pdf. Acesso em: 20 nov 2014.

BRASIL. Censo Escolar 2014. Rio de Janeiro: Instituto Nacional de Estudos e Pesquisas Educacionais Anísio Teixeira, 2014. Disponível em: http://www.qedu.org.br/escola/192834-joaocursino/censo-

escolar?year $=2014 \&$ dependence $=0 \&$ localization $=0$ \&education_stage $=0 \&$ item $=$. Acesso em: $27 \mathrm{abr}$ 2016.

BRASIL. Lei de Diretrizes e Bases da Educação Nacional. Lei n ${ }^{\circ}$ 9.394, de 20 de dezembro de 1996. Estabelece as diretrizes e bases da educação nacional, 1996. Disponível em http://portal.mec.gov.br/arquivos/pdf/ldb.pdf. Acesso em: 24 nov 2014.

CAMARGO, D.; BULGACOV, Y. L. M. A perspectiva estética e expressiva na escola: articulando conceitos da psicologia sócio-histórica. Psicologia em estudo, v.13, n.3, p.467-475, 2008. Disponível em: http://www.scielo.br/pdf/pe/v13n3/v13n3a07. Acesso em: 27 maio 2013.

CANDIDO, A. O direito à literatura. In: Vários escritos. São Paulo: Duas cidades, 1988. p.169-191.

DI PIERRO, M. C. Notas sobre a redefinição da identidade e das políticas públicas de educação de jovens e adultos no Brasil. Educação \& Sociedade, v.26, n.92, p. 1115-1139, 2005. Disponível em: http://www.scielo.br/pdf/es/v26n92/v26n92a18.pdf. Acesso em: 20 nov 2014.

DI PIERRO, M. C. A educação de jovens e adultos no plano nacional de ecucação: avaliação, desafios e perspectivas. Educação \& Sociedade, v.31, n.112, p. 939-959, 2010. Disponível em: http://www.scielo.br/pdf/es/v31n112/15.pdf. Acesso em: 20 nov 2014.

DUARTE, R. Cinema \& Educação. 3.ed. Belo Horizonte: Autêntica, 2009.

ECO, H. Confissões de um jovem romancista. São
Paulo: Cosac Naify, 2013.

FREIRE, P. Pedagogia da autonomia: saberes necessários à prática educativa. 25.ed. São Paulo: Paz e Terra, 2002.

GASPARIN, J. L. Uma didática para a pedagogia histórico-crítica. 3.ed. Campinas: Autores Associados, 2005.

GULLAR, F. Dentro da noite veloz. Rio de Janeiro: José Olympio, 1975.

LEONTIEV, A. O desenvolvimento do psiquismo. Lisboa: Livros Horizonte, 1978. 350p.

LIBERDADE é Azul, A. Direção: Krzysztof

Kieslowski. Produção: Marin Karmitz. Intérpretes: Juliette Binoche; Benoît Régent; Hélène Vincent; Florence Pernel; Charlotte Véry; Emmanuelle Riva e outros. Roteiro: Krzysztof Kieslowski. [S.1]: MK2 Productions; CED Productions; France 3 Cinéma; CAB Productions; Zespol Filmowy "Tor"; Canal+; Centre National de la Cinématographie (CNC); Fonds Eurimages du Conseil de l'Europe, 1993. 1 DVD (100 min), son., color., $35 \mathrm{~mm}$.

LOPES, A. I. L. S. Literatura e ética: experiências de leitura em contexto de ensino. 2012. 126f. Dissertação (Mestrado em Estudos Portugueses). Faculdade de Ciências Sociais e Humanas. Universidade Nova Lisboa, 2012. Disponível em: https://run.unl.pt/handle/10362/7285. Acesso em: 03 set 2014 .

MARTINS, L. M. Sobre o processo funcional imaginação. In: _. O desenvolvimento do psiquismo e a Educação escolar: contribuições à luz da psicologia histórico-cultural e da pedagogia histórico-crítica. Campinas: Autores Associados, 2013. p.226-241.

QUEIRÓS, B. C. O livro é passaporte, é bilhete de partida. In: ABREU, J. (Org.). Sobre ler, escrever e outros diálogos. Belo Horizonte: Autêntica, 2012. p.61-62.

ROSA, J. G. A Boiada. Rio de Janeiro: Nova Fronteira, 2011.

ROSA, J. G. Primeiras Estórias. 5.ed. Rio de 
Janeiro: José Olympio, 1969.

SARAIVA, T. Papel da Educação. Rio de Janeiro: Instituto de Administração do Rio de Janeiro, 2013.

SAVIANI, D. Pedagogia histórico-crítica: primeiras aproximações. 3.ed. São Paulo: Cortez / Autores Associados, 1992.

SCHROEDER, S. C. N. A arte como linguagem: um olhar sobre as práticas de educação infantil. Leitura: teoria \& prática. Ano 30, n.58, p.77-85,
2012.

ZANELLA, A. V.; CABRAL, M. G.; MAHEIRIE, K.; DA ROS, S. Z.; URNAY, L. C.; TITON, A. P.; WERNER, F. W.; SANDER, L. Relações estéticas, atividade criadora e constituição do sujeito: algumas reflexões sobre a formação de professores (as). Cadernos de Psicopedagogia, v.6, n.10, 2006. Disponível em: pepsic.bvsalud.org/pdf/cap/v6n10/v6n10a02.pdf. Acesso em: 13 jun 2014.

\section{Sobre os autores}

Denise Stefanoni Combinato é graduada em Psicologia e doutora em Saúde Coletiva (Unesp). Atualmente, é Psicóloga (Orientadora Educacional) e Professora do Departamento de Humanidades no Instituto Tecnológico de Aeronáutica (ITA).

João Mário de Medeiros Paixão é graduado em Engenharia Mecânica-Aeronáutica pelo Instituto Tecnológico de Aeronáutica.

Recebido em julho de 2016.

Aprovado em novembro de 2016. 